\title{
CHRONIC SMOKING AND ITS EFFECT ON ARTERIAL STIFFNESS
}

\author{
Svatopluk Binder ${ }^{\mathrm{a}}$, Kamil Navratil ${ }^{\mathrm{b}}$, Jan Halek ${ }^{\mathrm{a}}$ \\ a Department of Medical Biophysics, Faculty of Medicine and Dentistry, Palacky University in Olomouc \\ Clinic of Transplantant Surgery IKEM, Praha \\ e-mail: svatopluk.binder@email.cz
}

Received: April 29, 2008; Accepted (with revision): October 23, 2008

Keywords: Pulsewave/Arterial stiffness/Chronic smoking/Radial artery

\begin{abstract}
Aims: The goal of this study was to investigate the effect of chronic smoking on arterial stiffness at a peripheral site using pulse wave analysis.

Methods: Forty two non-smokers (17 males, 25 females) of average age $20.2 \pm 1.3$ year and forty five smokers (19 males, 26 females) of average age $24.3 \pm 2.4$ year were included in the study. Four parameters, SI (stiffness index), RI (reflection index), CT (crest time) and IWD (interwave distance) were evaluated by means of an adapted device based on pletysmographic principles that transform volume changes to voltage changes.

Results: SI corresponding to pulse wave velocity was $0.64 \mathrm{~m} / \mathrm{s}$ higher in smokers than in non-smokers $(7.25 \pm$ $0.53 \mathrm{~m} / \mathrm{s}$ versus $7.89 \pm 0.73 \mathrm{~m} / \mathrm{s}, \mathrm{P}<0.001)$. RI was significantly higher in smokers $(42.49 \pm 6.71 \%$, versus $35.46 \pm$ $0.06 \%, \mathrm{P}<0.001)$ than in non-smokers. IWD for non-smokers was $8.01 \pm 0.13 \%$, in smokers we found a $16 \%$ increase to $9.21 \pm 0.83 \%(\mathrm{P}<0.001)$. We detected a small increase in CT in smokers compared to non-smokers $(0.09 \pm 0.01 \mathrm{~s}$ versus $0.10 \pm 0.01 \mathrm{~s}, \mathrm{P}<0.005)$.

Conclusions: Chronic tobacco smoking is associated with endothelial dysfunction. In smokers we found increased values for all assessed parameters. Our results suggest that the negative effect of cigarette smoking on the vascular system can be found even in young smokers who have been smoking for less than 10 years.
\end{abstract}

\section{INTRODUCTION}

Arterial stiffness is considered to be one of the factors that play a considerable role in various pathophysiological processes such as atherosclerosis, left ventricular hypertrophy and aneurysm. Arterial stiffness can be measured using invasive and non-invasive methods. Pulse wave analysis is one of many methods used to assess arterial stiffness. The most popular non-invasive methods are based on pletysmographic principles. Others include computer oscilometry, ultrasonography and applied tonometry. Pulse wave contour consists of two main components: the first is caused by systolic pressure wave that results from blood ejection from the left cardiac chamber to aorta and its consequent distribution to peripheral sites. The second component is formed by pressure wave reflected back to the aorta from the lower body continuing to the upper limbs. The shape of the pulse wave is determined by a number of factors. Most frequent monitored factors are age, sex, body height, pulse and physical fittness ${ }^{1}$. Pulse wave analysis is also often used for predicting cardiovascular diseases. Smoking is one of the most important determinants of increased arterial stiffness and this accelerates the sclerotic process. Smoking even a single cigarette leads to short-term rise in arterial wall stiffness and increase in heart rate ${ }^{2}$. Smoking not only accelerates endothelial dysfunction in the large arteries, it is also responsible for changes in the physical properties of arterioles and small arteries $^{3}$. Vascular endothelium produces a number of mediators including nitric oxide (NO) which regulates arte- rial wall stiffness owing to smooth muscle tone changes ${ }^{4}$. McWeigh et al showed that cigarette smoking triggers NO production damage ${ }^{5}$. The vascular endothelium produces a number of substances that affect arterial stiffness. Basic structural factors determining arterial stiffness are predominantly colagen, elastin and transmural pressure. The most well-known vasodilatators are ET-1 (endothelin-1), adrenaline and noradrenaline. Inverse effect shows vasodilatators as for example glyceryl trinitrate, NO, ANP (atrial natriuretic peptide) $\left(\right.$ ref. $\left.^{6}\right)$.

The aim of this study was to test the effect of chronic smoking on arterial stiffness. In this research we evaluated the following parameters, SI (stiffness index), RI (reflection index), CT (crest time) and IWD (interwave distance).

\section{MATERIALS AND METHODS}

\section{Description of measurement technique}

Pulse wave recordings were made by use of a device invented at the Institute of Medical Biophysics, Medical Faculty, Palacky University in Olomouc. The main principle of this device is conversion of pressure changes to voltage changes by means of differential pressure transducer with two inputs, positive and negative. Volume changes generated by pulse waves are transformed into pressure changes and are brought to a positive input. A tonometer with pump is connected to negative input and this enables regulation of compensation pressure to pulse point. The 
measuring probe consists of metal tube with a diameter of $10 \mathrm{~mm}$. There is a thin elastic membrane attached on its end which has a convex form as a result of the internal pressure of liquid media. The membrane of the measuring probe is pressed down to the pulse point on artery and volume differences are transformed to voltage and then transmitted to measuring card which is plugged into a computer. Generated pulse waves are analysed in a programme that was created in LabVIEW software. A sampling frequency is $500 \mathrm{~Hz}$ and time of recording is 30 second.

\section{Subjects}

Measurements in our study were conducted on the radial artery in a group consisting of young smokers who have been smoking for 5-10 years. These results were compared to the results of measurement carried out on group of non-smokers of the same age. According to WHO, smoking is classified as mental and behavioural disorder due to use of tobacco (diagnosis F17). The male/female smokers smoked an average of 13 , respectively 9 cigarettes per day. An average period of smoking male smokers was 7.2 \pm 1.5 year for male smokers and $6.1 \pm 1.1$ year for female smokers. The first group of smokers included 45 probands ( 19 males and 26 females) and the second group of non-smokers included 42 subjects ( 17 males and 25 females). None had ever suffered from cardiovascular disease or had taken medicine with effects on the cardiovascular system. All respondents were acquainted with the measuring method and subscribed to the informed consent. To prevent contamination of the results of the influence of acute smoking all subjects were asked to abstain from smoking at least 12 hours before measurement. Each subject was left 5 minutes resting in a quiet room to stabilize the values of blood pressure and heart rate. The blood pressure and heart rate recordings were then measured by cardiomonitor LVM 130. The results of anthropometric, blood pressure and heart rate values are summarized in Table 1. The left radial artery was used for measurement of pulse wave. The measuring probe was placed on a palpation spot on the artery and as soon as the signal was strong enough a 30 second recording of signal commenced.

\section{Analysis}

We designed a simple programme for assessing pulse wave characteristics. In our study we used four parameters, reflection index (RI), stiffness index (SI), interwave distance (IWD) and crest time (CT). All parameters and their definitions are shown in Figure 1. The time difference between the peaks of the two components, known as the reflection time, is inversely proportional to arterial stiffness. To correct for the size of the subject, the reflection time is divided by the height of the subject. The resultant value is SI, which is expressed in meters/second. SI is comparable to the definitive measure of arterial stiffness, the pulse wave velocity (PWV). RI is a measure of vascular tone. It is calculated by dividing the height of the systolic component by the height of the diastolic component. This ratio is expressed as a percentage. IWD is defined as a ratio of width of the systolic peak in $2 / 3$ of its height from the bottom to total time duration of one single pulse wave and is expressed as a percentage. The last examined parameter is CT which is defined as a time of pulse wave propagation from the start until it reaches the systolic peak. From every recording we obtained ten values, averaged them and found the standard deviation. The data in Table 2 present averaged values and the standard deviations of all recordings for both groups. To test statistical significance we used the Student t-test for independent samples.

\section{Results}

The demographic and hemodynamic profiles of smokers and nonsmokers are shown in Table 1. We found no significant differences in blood pressure or heart rate between smokers and nonsmokers. RI was significantly higher in smokers $(42.49 \pm 6.71 \%$, versus $35.46 \pm 0.06 \%$, $\mathrm{P}<0.001)$ than in non-smokers. The interwave distance IWD value for non-smokers was $8.01 \pm 0.13 \%$, in smokers we found a $16 \%$ increase to $9.21 \pm 0.83 \%$ ( $\mathrm{P}<0,001)$. SI corresponding to pulse wave velocity was $0.64 \mathrm{~m} / \mathrm{s}$ higher

Table 1. Subjects‘ baseline characteristics. Data are expressed as means \pm standard deviation

\begin{tabular}{|l|c|c|}
\hline & Nonsmokers & Smokers \\
\hline Sex [males/females] & $17 / 25$ & $19 / 26$ \\
\hline Age [years] & $20 \pm 1$ & $24 \pm 2$ \\
\hline Body height [cm] & $175.3 \pm 6.2$ & $177.5 \pm 5.1$ \\
\hline Weight [kg] & $69.0 \pm 9.5$ & $70.6 \pm 9.4$ \\
\hline BMI [ kg/m2] & $22.5 \pm 2.8$ & $22.6 \pm 2.3$ \\
\hline Brachial systolic pressure $[\mathrm{mmHg}]$ & $119 \pm 8$ & $120 \pm 9$ \\
\hline Brachial diastolic pressure $[\mathrm{mmHg}]$ & $74 \pm 8$ & $77 \pm 7$ \\
\hline Heart rate $\left[\mathrm{min}^{-1}\right]$ & $75 \pm 8$ & $76 \pm 8$ \\
\hline
\end{tabular}




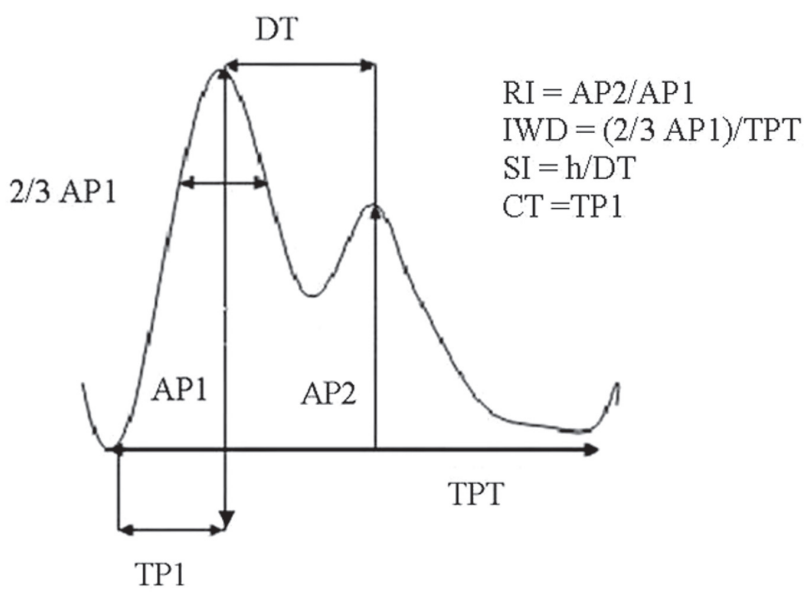

Fig. 1. Pulse wave contour and definitions of evaluated parameters

in smokers than in nonsmokers $(7.25 \pm 0.53 \mathrm{~m} / \mathrm{s}$ versus $7.89 \pm 0.73 \mathrm{~m} / \mathrm{s}, \mathrm{P}<0.001)$. The last evaluated parameter was CT. We detected a small increase in smokers compared to non-smokers $(0.09 \pm 0.01 \mathrm{~s}$ versus $0.10 \pm 0.01 \mathrm{~s}$, $\mathrm{P}<0.005)$.

\section{Discussion}

Endothelial damage is a central feature in the evolution of vascular disease induced by cigarette smoking and may act as a precursor for future atherosclerosis. Measuring arterial stiffness provides good data on the endothelial condition. Arterial stiffness can be analyzed using the technique of pulse wave analysis. One of the many risk factors associated with endothelial dysfunction is smoking which is presumed to be responsible for development of cardiovascular disease. Chronic smoking damages skin microcirculation independently to endothelium and is linked with skin vasodilatation. Even in light smokers who do not smoke more than 20 cigarettes per day can be detected changes in arterial elasticity ${ }^{7}$. Recent research in this field suggests that vascular function is improved even after six months after quitting smoking ${ }^{8}$. Rehill et all claim that positive changes in arterial elasticity can be seen even after 4 weeks of cigarette abstinence ${ }^{9}$. The influence of chronic smoking on arterial stiffness and wave reflection can be several-times higher combined with caffeine. Barua et all assume that the extent of damage of endothelial vasoregulation activity and NO biosynthetise pathways does not depend on the number of smoked cigarettes per day ${ }^{10}$. In our study we used SI which substitutes pulse wave velocity (PWV). It has been proved that SI positively correlates with $\mathrm{PWV}^{11}$. SI values are mainly influenced by large artery stiffness but they can be also affected by wave reflection from peripheral sites as well as from large arteries $^{11,12}$. For smokers we detected higher values of SI which indicate increased arterial stiffness. To determine vascular tone we used the parameter RI. Peripheral vasodilatation increases with decreasing RI. The use of vasodilatator GTN (glyceryl trinitrate) causes decrease in RI values so it can be assumed that nicotine as vasoconstrictor could have an opposite effect on changes in tone of small arteries $^{11}$. We registered $20 \%$ increase in smokers compared to non-smokers which shows increased vascular vasoconstriction and pressure wave reflection ${ }^{13}$. Other assessed parameters were CT and IWD. Pathological changes to the cardiovascular system can be detected by means of CT. Oliva and Roztočil used CT in studying obliterated atherosclerosis and smoking is also a risk factor ${ }^{14}$. It was also proved that CT prolongs in diabetic patients with neuropathy ${ }^{15}$. We monitored only $10 \%$ increment therefore this parameter does not predict any marked deterioration in arterial wall caused by chronic smoking. IWD can be also used in evaluation of vascular system condition and it has been proved that risk of cardiovascular system impairment multiplies with age and number of smoked cigarettes ${ }^{14}$. IWD in smokers demonstrated $17 \%$ increment in comparison with nonsmokers.

\section{CONCLUSION}

Chronic smoking is a leading risk factor in development cardiovascular diseases. We used non-invasive measuring device to assess how chronic smoking impairs arterial elasticity. In our research we evaluated four parameters, SI, RI, CT and IWD. Our data showed pronounced increase in SI, RI and IWD indicating increased arterial stiffness. This suggests that even young smokers have damaged vascular endothelium, which can lead to increased arterial stiffness and consequently to overall deterioration of the cardiovascular system condition.

\section{ACKNOWLEDGEMENTS}

This work was pupported by the Ministry of Education of the Czech Republic MSM 6198959216 and MSM 6198959215.

Table 2. Evaluated parameters of pulse wave for nonsmokers and smokers.

Data are expressed as means \pm SD

\begin{tabular}{|l|l|l|l|l|}
\hline & RI [ \%] & IWD [\% ] & SI [m/s] & CT [s] \\
\hline Nonsmokers & $35.46 \pm 0.06$ & $8.01 \pm 0.13$ & $7.25 \pm 0.53$ & $0.09 \pm 0.01$ \\
\hline Smokers & $42.49 \pm 6.71$ & $9.21 \pm 0.83$ & $7.89 \pm 0.73$ & $0.10 \pm 0.01$ \\
\hline P- values & $<0.001$ & $<0.001$ & $<0.001$ & $<0.005$ \\
\hline
\end{tabular}




\section{REFERENCES}

1. O'Rourke MF, Pauca A, Juany X-J. Pulse wave analysis. British Journal of Clinical Pharmacology, 2001; 6:507-522.

2. Kool MJF, Hoeks APG, Boudier HAJ, Reneman RS, Van Bortel LM. Short- and long-term effects of smoking on arterial wall properties in habitual smokers. Journal of the American College of Cardiology, 1993; 22:1881-1886.

3. Auerbach D, Hammond EC, Garfinkel L. Thickening of walls of arterioles and small arteries in relation to age and smoking habits. The New England Journal of Medicine, 1968; 278:908-984.

4. Wilkinson IB, Qasem A, McEniery CM, Webb DJ, Avolio AP, Cockcroft JR. Nitric Oxide Regulates Local Arterial Distensibility In Vivo. Circulation, 2002; 105:213-217.

5. McVeigh GE, LeMay L, Morgan DJ, Cohn JN. The effect of chronic cigarette smoking on endothelium-dependent responses in humans. The American Journal of Cardiology, 1996; 78:668672.

6. Nichols WW, O'Rourke MF. McDonald's Blood Flow in Arteries: Theoretical, Experimental and Clinical Principles. 1998, $4^{\text {th }}$ ed., Arnold, London.

7. Zimlichman R, Boaz M, Duprez D, Rahn K-H, Rizzoni, D, Payeras AC, Hamm C. Effects of moderate smoking on arterial elasticityin healthy European population- the seven European sites study of arterial elasticity. American Journal of Hypertension, 2003; 5:149-150.
8. Oren S, Isakov I, Golzman B, Kogan J, Turkot S, Peled R, Josefy C. The influence of smoking cessation on hemodynamics and arterial compliance. Angiology, 2006; 57:564-568.

9. Rehill N, Beck CR, Yeo KR,Yeo WW. The effect of chronic tobacco smoking on arterial stiffness. British Journal of Clinical Pharmacology, 2006; 61:767-773.

10. Barua RS, Ambrose JA, Eales-Reynoldas LJ. Heavy and light cigarette smokers have similar dysfunction of endothelial vasoregulatory activity: An in vivo and in vitro correlation. Journal of the American College of Cardiology, 2002; 39:758-63.

11. Millasseau SC, Kelly RP, Ritter JM, Chowienczyk PJ. Determination of age-related increases in large artery stiffness by digital pulse contour analysis. Clinical Science, 2002; 103:371-377.

12. Woodman RJ, Watts GF, Kingwell BA, Dart AM. Interpretation of the digital volume pulse: its relationship with large and small artery compliance. Clinical Science, 2003; 3:283-285.

13. Philip J. Chowienczyk PJ, Belly RP,MacCallum H, Millasseau SC, Andersson TLG, Gosling RG, Ritter JM, Änggärd EE. Photoplethysmographic Assessment of Pulse Wave Reflection Blunted Response to Endothelium-Dependent Beta2-Adrenergic Vasodilation in Type II Diabetes Mellitus Beta2-Adrenergic Vasodilation in Type II Diabetes Mellitus Journal of the American College of Cardiology, 1999; 34:2007-2014.

14. Oliva I, Roztočil K. Pulsová vlna v diagnostice ischémické choroby dolních končetin. Prague, Avicenum, 1982.

15. Lefrandt JD. Autonomic Dysfunction in Cardiovascular Disease. Faciltair Bedrijf RUG, Groningen; 2006. 